\title{
Commentary
}

\section{The CpG Island Methylator Phenotype in Colorectal Cancer}

\author{
Wade S. Samowitz \\ From the University of Utah Health Sciences Center, Department \\ of Anatomic Pathology, Salt Lake City, Utah
}

The concept of a CpG island methylator phenotype, or CIMP, has had a complicated and somewhat controversial history. CIMP refers to the notion that a subset of tumors has widespread methylation of $\mathrm{CpG}$ islands that leads to epigenetic inactivation of tumor suppressor genes by promoter methylation. ${ }^{1}$ Perhaps the best accepted example of this is sporadic colorectal tumors with microsatellite instability. These tumors exhibit extensive $\mathrm{CpG}$ island methylation, and their instability, in most cases, is due to promoter methylation of one of the DNA mismatch repair genes, $h M L H 1 .^{2}$ In contrast, microsatellite instability in tumors associated with hereditary nonpolyposis colorectal cancer (HNPCC) is due to a germline mutation in one of the mismatch repair genes. The concept of CIMP has not, however, been universally accepted, especially with respect to colorectal tumors without microsatellite instability. ${ }^{3}$

The study by Ogino et $\mathrm{al}^{4}$ in the current issue of The Journal of Molecular Diagnostics represents a significant advance in the field of CIMP. This study of over 900 colorectal tumors uses a quantitative method for characterization of $\mathrm{CpG}$ island methylation status and evaluates multiple panels of CpG islands for the classification of CIMP. Although questions remain, a strong implication of this study is that this method may be used to help determine which microsatellite unstable tumors are sporadic and which are associated with HNPCC. In this Commentary, we will give a brief background of CIMP, discuss the contribution of the Ogino et al study, ${ }^{4}$ and then detail unanswered questions and future directions for research.

\section{Background}

CIMP was originally described in colorectal cancer by Toyota et al in 1999. ${ }^{1}$ This and subsequent studies identified a number of relationships between CIMP and various clinicopathological parameters, including microsatellite instability, proximal location, mutant Ki-ras, wild-type $p 53$, female gender, older age, and, especially, the BRAF
V600E mutation. ${ }^{1,5-9}$ The concept of CIMP was challenged, however, since it was asserted that the division of CIMP-negative and CIMP-positive tumors was arbitrary and that without inclusion of microsatellite unstable tumors, most of the reported relationships, other than older age and proximal location, would disappear. ${ }^{3}$ Our multivariate analysis of colon tumors showed that this was not the case, since significant relationships were seen in the subset of tumors without microsatellite instability and with factors besides age and location, including the BRAF V600E mutation, Ki-ras mutations, and higher stage. ${ }^{2}$ However, a bimodal distribution of microsatellite stable colon cancers with respect to CIMP was not seen.

Many of these studies, including our own, used the socalled classic panel of CpG islands: $h M L H 1, p 16$, and MINTS (methylated in tumors ${ }^{1}$ ) 1, 2, and 31, and also used methylation-specific polymerase chain reaction $(\mathrm{PCR})^{10}$ to determine the methylation status of the respective CpG island. The next major development was by Weisenberger et al. ${ }^{11}$ They used MethyLight technology and an unsupervised two-dimensional cluster analysis of DNA methylation data to identify CpG island panels in which CIMP classification showed a very strong relationship to BRAF V600E mutations, seemed to be associated with nearly every sporadic microsatellite unstable tumor, and, for the first time, showed a bimodal distribution with respect to colorectal cancers, implying that the distinction between CIMP-positive and -negative was not arbitrary (as had been previously suggested $^{3}$ ). A five-marker CpG island panel (CACNA1G, IGF2, NEUROG1, RUNX3, and SOCS1) was identified that demonstrated both bimodality and robust performance on formalin-fixed, paraffin-embedded tissue.

W.S. is a medical director at ARUP Laboratories and receives partial research support from the ARUP Institute for Clinical and Experimental Pathology

Accepted for publication February 26, 2007

This commentary relates to Ogino et al, J Mol Diagn 2007, 9:305-314, published in this issue.

Address reprint requests to Wade S. Samowitz, M.D., University of Utah Health Sciences Center, Department of Pathology, 50 North Medical Dr., Salt Lake City, UT 84132. E-mail: wade.samowitz@aruplab.com. 


\section{The Current Study}

The study by Ogino et al ${ }^{4}$ takes the necessary step of validating the $\mathrm{CpG}$ island panels and methods proposed by Weisenberger et $\mathrm{al}^{11}$ in a different and larger set of colorectal tumors. This elegant study compares several modifications of the panels initially proposed by Weisenberger et al, ${ }^{11}$ shows that they are essentially identical in their classification of CIMP, and even defines a slightly different and, perhaps more manageable, panel of four CpG islands (RUNX3, CACNA1G, IGF2, and hMLH1) that demonstrate very high sensitivity and specificity for CIMP. The excellent bimodal distribution of CIMP in microsatellite unstable tumors demonstrated by Ogino et $\mathrm{al}^{4}$ suggests that this approach may prove useful for the diagnostic work-up of HNPCC, since CIMP-high microsatellite unstable tumors are very likely to be sporadic.

As might be expected, however, some differences with Weisenberger et $\mathrm{al}^{11}$ were noted in this larger sample. The original study stated that with one exception all microsatellite unstable cancers could be explained by either an HNPCC germline mutation or by CIMP-high associated with hMLH1 methylation. In the current study, close to $20 \%$ of microsatellite unstable tumors were CIMP-negative; although Ogino et al ${ }^{4}$ have not evaluated the individuals with microsatellite unstable tumors for germline mismatch repair gene mutations, they did conclude that it is unlikely that all of these $20 \%$ are due to HNPCC. We have observed a similar group of apparently non-HNPCC, CIMP-negative tumors in our dataset, ${ }^{2}$ and Oliveira et $\mathrm{al}^{12}$ observed that approximately $40 \%$ of sporadic unstable tumors lacked hMLH1 methylation. If true, this has important implications for the interpretation of CIMP in the context of the work-up for HNPCC. Whereas CIMP-high, microsatellite unstable tumors may be reliably regarded as sporadic, it seems imprudent at the present time to regard all microsatellite unstable, CIMP-negative tumors as necessarily HNPCCassociated. This is similar to the situation with BRAF V600E mutations in microsatellite unstable cancers: the presence of a mutation is strong evidence that the tumor is sporadic, whereas the absence of the mutation suggests that the tumor may be either sporadic or HNPCC-associated. ${ }^{13-15}$

Another difference is that the relationship between CIMP and BRAF V600E mutations, at least in tumors without microsatellite instability, appears not to be as strong in the study by Ogino et al ${ }^{4}$ (using their criteria for CIMP-high) as that in Weisenberger et al. ${ }^{11}$ In the previous study, only two of 26 cancers (8\%) with BRAF mutations occurred in tumors that were not CIMP-high ${ }^{10}$ (although this analysis did include microsatellite unstable cancers). In the current study, depending on the cut-off used for CIMP-high, approximately 40 to $60 \%$ of microsatellite stable tumors with BRAF mutations occurred in tumors that were not CIMP-high. It should be noted that this also does not compare well with our previous results using the classic $\mathrm{CpG}$ island panel and methylationspecific PCR, as in that study only three of $35(9 \%)$ microsatellite stable cancers with BRAF mutations occurred in tumors that were not CIMP-high. ${ }^{2}$

Finally, although Ogino et $\mathrm{al}^{4}$ demonstrate a very impressive (and, probably, diagnostically useful) bimodal distribution for CIMP in microsatellite unstable tumors, no such bimodal distribution is seen for microsatellite stable tumors. This is very similar to our results using the classic panel of $\mathrm{CpG}$ islands and methylation-specific PCR, although the bimodal distribution for unstable tumors in our dataset is not as distinct. ${ }^{2}$ This result of Ogino et al ${ }^{4}$ may not even be a difference from that originally reported by Weisenberger et al, ${ }^{11}$ since that study did not separately report distributions for microsatellite stable and unstable cancers. At any rate, the lack of a bimodal distribution of CIMP, and therefore the arbitrary designation of this parameter, if unstable tumors are excluded was one of the original criticisms of the concept of CIMP; although $w^{2}$ have shown important relationships between CIMP in stable tumors and a variety of clinicopathologic variables, especially BRAF mutations, this remains an unresolved issue.

\section{Future Directions}

Although Ogino et al ${ }^{4}$ have made great strides in describing a panel and technique for CIMP determination that will probably have important diagnostic implications, there are still unanswered questions regarding CIMP. One is which technique is the best for determination of methylation. Whereas Weisenberger et $\mathrm{al}^{11}$ and Ogino et $\mathrm{al}^{4}$ make a strong case for MethyLight, other techniques have been used, including methylation-specific PCR and pyrosequencing. ${ }^{16}$ We are unaware of a study that directly compares these techniques, although such studies may be underway.

The main unresolved issue with CIMP is which panel is the best for CIMP determination, or whether even one panel will suffice. The major problem with this is that there is no gold standard for CIMP; both Ogino et $\mathrm{al}^{4}$ and Weisenberger et al ${ }^{11}$ use surrogate markers (such as relationships to BRAF and/or Ki-ras mutations or microsatellite instability) as a way to argue that a particular panel is better than another. Although no other obvious method is available at this time, there are suggestions that this does not necessarily result in an optimal panel, at least for all subsets of tumors. We would argue that the strongest results using these panels are for microsatellite unstable tumors, where there is an obvious bimodal distribution and very strong relationships with BRAF and Ki-ras mutations (direct and inverse, respectively). The situation is not so clear for microsatellite stable tumors, however. As noted above, the classic panel was much more sensitive for BRAF mutations in microsatellite stable tumors in our dataset ${ }^{2}$ as compared with Ogino et al. ${ }^{4}$ In addition, in a recent study that related CIMP to cigarette smoking, we identified a significant relationship between smoking and CIMP-high, BRAF wild-type tumors, ${ }^{17}$ a relationship that might not have been seen if we had used a definition of CIMP that was more specific for BRAF mutations (as in Weisenberger et al ${ }^{11}$ or Ogino et al ${ }^{4}$ ). There has been a suggestion in the literature that three classifications of CIMP exist: CIMP-negative, CIMP-low, and CIMP-high. We have noted that BRAF mutations are associated with very high degrees of methylation, and 
Ogino et al ${ }^{4}$ have previously proposed that a CIMP-low classification may exist that is related to Ki-ras mutations rather than BRAF. ${ }^{17,18}$ The classic CIMP panel, precisely because it is not as tightly linked to BRAF mutations as those proposed by Ogino et al, ${ }^{4}$ shows direct relationships with both Ki-ras and BRAF, mutations that are mutually exclusive because they occur in the same pathway. ${ }^{19}$ This suggests that the classic panel is combining, to a certain extent, the CIMP-low and CIMP-high categories. This may be more useful for epidemiological studies than the new proposed panels. At any rate, we do not feel that the optimal panel or panels for CIMP have been as yet identified, and future research should try to determine such panels but also take this uncertainty into account.

In summary, this elegant study by Ogino et $\mathrm{al}^{4}$ performs an essential validation of the findings of Weisenberger et $\mathrm{al}^{11}$ and also points to some differences with the previous study that may have implications for the interpretation of CIMP results in the work-up of HNPCC. Much work still needs to be done with respect to the optimal technique(s) and panel(s) for CIMP determination, but the diagnostic utility and epidemiology of this epigenetic change strongly support its significance in the biology of colorectal cancer.

\section{Acknowledgment}

I acknowledge the helpful comments of Antonia Sepulveda in preparing this commentary.

\section{References}

1. Toyota M, Ahuja N, Ohe-Toyota M, Herman JG, Baylin SB, Issa JP: $\mathrm{CpG}$ island methylator phenotype in colorectal cancer. Proc Natl Acad Sci USA 1999, 96:8681-8686

2. Samowitz WS, Albertsen H, Herrick J, Levin TR, Sweeney C, Murtaugh MA, Wolff RK, Slattery ML: Evaluation of a large, populationbased sample supports a CpG island methylator phenotype in colon cancer. Gastroenterology 2005, 129:837-845

3. Yamashita K, Dai T, Dai Y, Yamamoto F, Perucho M: Genetics supersedes epigenetics in colon cancer phenotype. Cancer Cell 2003, 4:121-131

4. Ogino S, Kawasaki T, Kirkner GJ, Kraft P, Loda M, Fuchs CS: Evaluation of markers for $\mathrm{CpG}$ island methylator phenotype (CIMP) in colorectal cancer by a large population-based sample. J Mol Diagn 2007, 9:305-314

5. Toyota M, Ohe-Toyota M, Ahuja N, Issa JP: Distinct genetic profiles in colorectal tumors with or without the CpG island methylator phenotype. Proc Natl Acad Sci USA 2000, 97:710-715

6. Hawkins N, Norrie M, Cheong K, Mokany E, Ku SL, Meagher A O'Connor T, Ward R: CpG island methylation in sporadic colorectal cancers and its relationship to microsatellite instability. Gastroenterology 2002, 122:1376-1387

7. van Rijnsoever M, Grieu F, Elsaleh H, Joseph D, lacopetta B: Characterisation of colorectal cancers showing hypermethylation at multiple CpG islands. Gut 2002, 51:797-802

8. Kambara T, Simms LA, Whitehall VL, Spring KJ, Wynter CV, Walsh MD, Barker MA, Arnold S, McGivern A, Matsubara N, Tanaka N, Higuchi T, Young J, Jass JR, Leggett BA: BRAF mutation is associated with DNA methylation in serrated polyps and cancers of the colorectum. Gut 2004, 53:1137-1144

9. Nagasaka T, Sasamoto H, Notohara K, Cullings HM, Takeda M, Kimura K, Kambara T, MacPhee DG, Young J, Leggett BA, Jass JR, Tanaka N, Matsubara N: Colorectal cancer with mutation in BRAF, KRAS, and wild-type with respect to both oncogenes showing different patterns of DNA methylation. J Clin Oncol 2004, 22:4584-4594

10. Herman JG, Graff JR, Myohanen S, Nelkin BD, Baylin SB: Methylation-specific PCR: a novel PCR assay for methylation status of CpG islands. Proc Natl Acad Sci USA 1996, 93:9821-9826

11. Weisenberger DJ, Siegmund KD, Campan M, Young J, Long TI, Faasse MA, Kang GH, Widschwendter M, Weener D, Buchanan D, Koh H, Simms L, Barker M, Leggett B, Levine J, Kim M, French AJ, Thibodeau SN, Jass J, Haile R, Laird PW: CpG island methylator phenotype underlies sporadic microsatellite instability and is tightly associated with BRAF mutation in colorectal cancer. Nat Genet 2006, 38:787-793

12. Oliveira C, Westra JL, Arango D, Ollikainen M, Domingo E, Ferreira A, Velho S, Niessen R, Lagerstedt K, Alhopuro P, Laiho P, Veiga I, Teixeira MR, Ligtenberg M, Kleibeuker JH, Sijmons RH, Plukker JT, Imai K, Lage P, Hamelin R, Albuquerque C, Schwartz Jr S, Lindblom A, Peltomaki P, Yamamoto H, Aaltonen LA, Seruca R, Hofstra RM: Distinct patterns of KRAS mutations in colorectal carcinomas according to germline mismatch repair defects and hMLH1 methylation status. Hum Mol Genet 2004, 13:2303-2311

13. Deng G, Bell I, Crawley S, Gum J, Terdiman JP, Allen BA, Truta B, Sleisenger MH, Kim YS: BRAF mutation is frequently present in sporadic colorectal cancer with methylated $\mathrm{hMLH1}$, but not in hereditary nonpolyposis colorectal cancer. Clin Cancer Res 2004, 10:191-195

14. Domingo E, Laiho P, Ollikainen M, Pinto M, Wang L, French AJ, Westra J, Frebourg T, Espin E, Armengol M, Hamelin R, Yamamoto H, Hofstra RM, Seruca R, Lindblom A, Peltomaki P, Thibodeau SN, Aaltonen LA, Schwartz Jr S: BRAF screening as a low-cost effective strategy for simplifying HNPCC genetic testing. J Med Genet 2004, 41:664-668

15. McGivern A, Wynter CV, Whitehall VL, Kambara T, Spring KJ, Walsh MD, Barker MA, Arnold S, Simms LA, Leggett BA, Young J, Jass JR: Promoter hypermethylation frequency and BRAF mutations distinguish hereditary non-polyposis colon cancer from sporadic MSI-H colon cancer. Fam Cancer 2004, 3:101-107

16. Issa JP, Shen L, Toyota, M: CIMP, at last. Gastroenterology 2005, 129:1121-1124

17. Samowitz WS, Albertsen H, Sweeney C, Herrick J, Caan BJ, Anderson KE, Wolff RK, Slattery ML: Association of smoking, CpG island methylator phenotype, and V600E BRAF mutations in colon cancer. J Natl Cancer Inst 2006, 98:1731-1738

18. Ogino S, Kawasaki T, Kirkner GJ, Loda M, Fuchs CS: CpG island methylator phenotype-low (CIMP-low) in colorectal cancer: possible associations with male sex and KRAS mutations. J Mol Diagn 2006, 8:582-588

19. Rajagopalan H, Bardelli A, Lengauer C, Kinzler KW, Vogelstein B, Velculescu VE: Tumorigenesis: rAF/RAS oncogenes and mismatchrepair status. Nature 2002, 418:934 